\title{
Новая серия импульсных стабилизаторов напряжения - микросхемы 5320
}

\author{
В. Громов ${ }^{1}$, П. Ястребов ${ }^{2}$
}

УДК 621.382 | ВАК 05.27.0

\begin{abstract}
АО «Группа Кремний ЭЛ" представило новую серию импульсных стабилизаторов напряжения со встроенным силовым ключом - микросхемы 5320. Большое количество типов и типономиналов, входящих в серию, их функциональное разнообразие позволят потребителям микросхем разрабатывать новую аппаратуру значительно быстрее и качественнее, успешнее решать задачи импортозамещения. Микросхемы 5320 предназначены для применения в наземной и космической технике, авиации, надводной и подводной технике ВМФ, а также в общепромышленной аппаратуре.
\end{abstract}

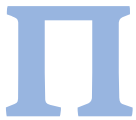

родукция АО «Группа Кремний ЭЛ» хорошо известна разработчикам источников вторичного электропитания (ИВЭП) и широко используется в серийной продукции, в новых разработках как гражданского, так и военного назначения. Это ШИМ-контроллеры под различные топологии преобразования, включая ШИМ-контроллер для топологий с активным демпфированием (Active Clamp), фазосдвигающий контроллер для резонансных преобразователей, контроллер выравнивания выходных токов для модулей ИВЭП, предназначенных для параллельной работы.

В то же время в рамках этой номенклатуры объем микросхем, включающих в свой состав силовые ключи, был незначительный. А ведь совмещение на одном кристалле и в одном корпусе микросхемы контроллера ИВЭП и силовых ключей - это наиболее значимое для повышения удельной мощности ИВЭП техническое решение
Для ликвидации пробела на предприятии сначала было разработано и освоено семейство микросхем (категория качества “ВП») со встроенным LDMOS силовым ключом на 3 А: 1290ЕФ1У (с регулируемым выходным напряжением), 1290ЕК2.5У, 1290ЕК3.3У, 1290ЕК5У, 1290ЕК12У (с фиксированными выходными напряжениями). Они поддерживают работу на частотах, значительно больших 1 МГц, требуют минимальной внешней обвязки (миниатюрный дроссель, диод Шоттки, входной, выходной и бутстрепный конденсаторы, RC-цепи коррекции и резистивный делитель для регулируемого варианта)

Затем была разработана и освоена в серийном производстве серия микросхем 5320 двойного назначения (категория качества «ВП»), о которой пойдет речь в статье. Перечень всех типономиналов микросхем серии, их основное функциональное назначение приведены в табл. 1. Там же приведены основные квалификационные

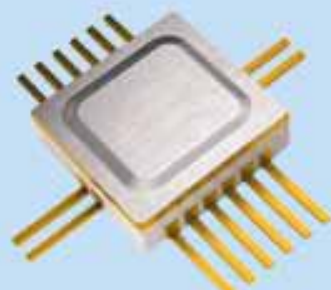

H04.16-2B

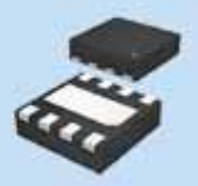

$5225.10-1$

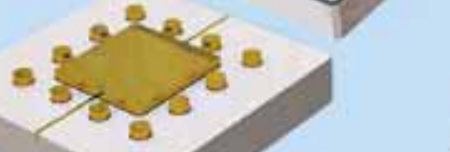

MK KT-119-1

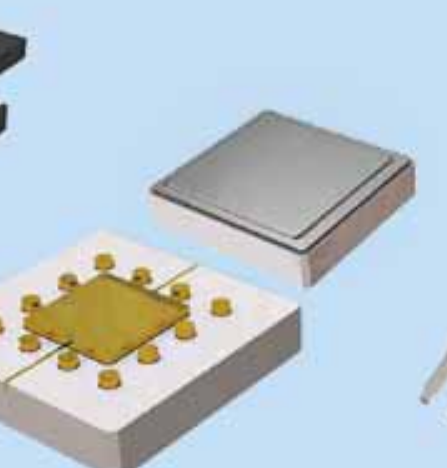

$1501.5-7$

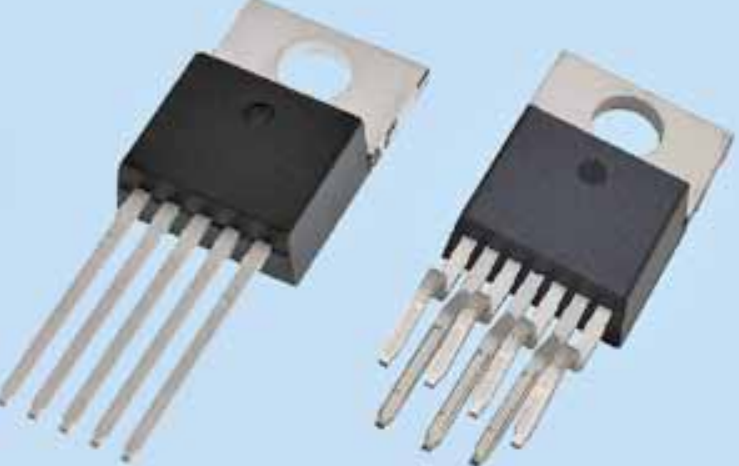

1505.7-D

Рис. 1. Используемые в серии 5320 корпуса микросхем (масштаб не соблюдается)

АО «Кремний ЭЛ», директор по проектам развития, член Общественного совета при Министерстве науки и высшего образования РФ, vladimir.gromov.50@yandex.ru.

АО «Кремний ЭЛ», главный конструктор дЦур, yastreb@sitsemi.ru. 
параметры, корпусное исполнение, обозначение технических условий (ТУ) и ближайший функциональный аналог. Все микросхемы этой серии рассчитаны на диапазон рабочих температур $-60 \ldots 125^{\circ} \mathrm{C}$ и имеют уровень радиационной стойкости 7.И - 2Ус, 7.K - 1К $\left(7 . \mathrm{K}_{11}\left(7 . \mathrm{K}_{12}\right)-\right.$ $\left.15 \mathrm{MэB} \cdot \mathrm{cm}^{2} / \mathrm{Mг}\right)$, подтвержденный соответствующими испытаниями. Поскольку микросхемы выделяют большое количество тепла при работе, в ТУ особо оговаривается максимальная рабочая температура корпуса. Все микросхемы имеют защиту по току и от перегрева кристалла. Новые металлокомпозитный корпус 5225.10-1 и металлокерамический корпус MК КT1191 (рис. 1) имеют металлическую монтажную площадку (под кристалл), выходящую из основания корпуса, предназначенную для пайки на печатную плату вместе с выводами корпуса. Такое решение корпуса существенно улучшает отвод тепла от кристалла микросхем.

Назначение микросхем серии 5320 - построение на их базе малогабаритных источников питания для широкой номенклатуры аппаратуры, включая комплексную аппаратуру с распределенной системой питания. Широкий диапазон входных напряжений стабилизаторов, ряд фиксированных выходных напряжений и наличие исполнений с регулируемым выходным напряжением позволяют легко выбрать подходящую микросхему под конкретное применение.

Зарубежные аналоги, указанные в табл. 1, надо рассматривать лишь как наиболее близкие функциональные аналоги, не всегда полные, и не pin to pin совместимые. Это отчасти объясняется двойным назначением разработанных микросхем. Применение микросхем в военной и аэрокосмической технике потребовало расширенный диапазон рабочих температур, упаковку кристаллов в металлокерамические корпуса, изменение конструкции для обеспечения стойкости к воздействию специальных факторов и надежности. Тем не менее, учитывая большую популярность упомянутых зарубежных аналогов у отечественных разработчиков ИВЭП, можно предполагать, что микросхемы серии найдут широкое применение при решении задач, связанных с импортозамещением продукции. Кроме корпусных исполнений микросхем в пластмассовых, металлокомпозитныхи металлокерамических корпусах (см. рис. 1), предусмотрено и бескорпусное исполнение микросхем. Негерметизированные кристаллы импульсных стабилизаторов могут найти применение в микросборках ИВЭП или в составе микросборок с расширенным функционалом.

Наличие на борту микросхем силовых ключей, на первый взгляд, предполагает простоту типовых схем применения: дроссель, диод Шоттки, входные, выходные конденсаторы, резистивный делитель обратной связи, корректирующая цепочка и всё. Но это обманчивая простота. Надежная работа зависит от правильного выбора этих немногочисленных элементов обвязки и от их взаимного с микросхемой расположения на печатной плате. В ТУ на микросхемы в разделах «Рекомендации по применению и эксплуатации" подробно описан выбор компонентов обвязки и возможных вариантов применений. Функциональные схемы микросхем серии приведены на рис. 2-9. На многих из них показан внутренний резистивный делитель R1, R2 на входе (FB), который задает выходное напряжение для типономиналов с фиксированным выходным напряжением. Для микросхем с регулируемым выходным напряжением (5320ЕA01, 5320ЕA02, 5320ЕA03,

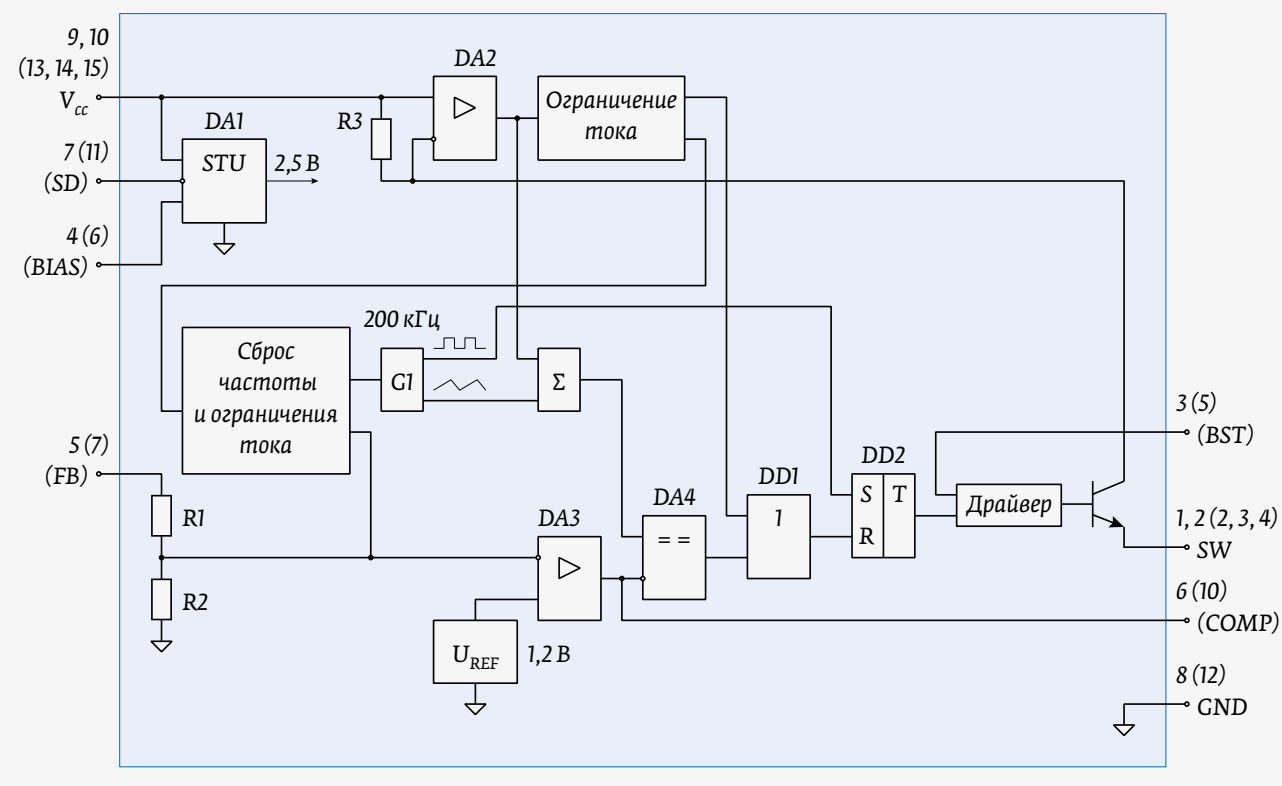

Рис. 2. Схема электрическая функциональная микросхем типа 5320ЕА01, 5320EB01 


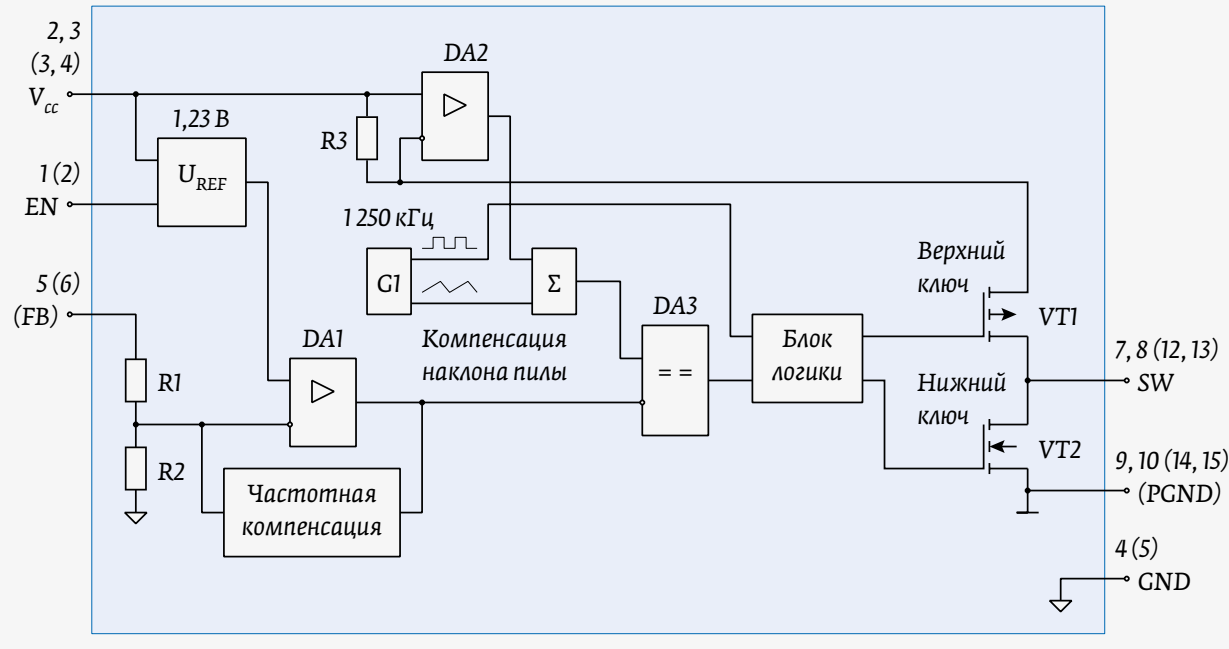

Рис. 3. Схема электрическая функциональная микросхем типа 5320ЕA02, 5320EB02

5320ЕA04 и 5320ЕА05) предполагается, что резистор R1 закорочен, а резистор R2 не подключен.

Микросхемы типа 5320EA01, 5320EB01 (см. рис. 2) выполнены по биполярной технологии и представляют собой понижающие преобразователи напряжения с токовым управлением (current mode) и с фиксированной частотой коммутации.

\section{Особенности микросхем 5320ЕА01, 5320ЕВ01:}

- диапазон напряжения питания от 3,6 до 30 В;

- выходной ток до 1 А;

- ограничение выходного тока в каждом такте;

- частота коммутации 200 кГц;

- снижение частоты коммутации при перегрузке;

- температурная защита;

- специальный драйвер силового ключа с бутстрепным питанием через вывод (BST) и со схемой ограничения насыщения;

- вывод (BIAS) предназначен для питания внутреннего стабилизатора микросхемы, для увеличения КПД можно подключить этот вывод к выходу преобразователя;

- вход (SD) для перевода микросхемы в режим с низким энергопотреблением.

Микросхемы типа 5320ЕA02, 5320ЕВ02 (см. рис. 3) выполнены по БиКМОП-технологии и представляют собой понижающие преобразователи напряжения с синхронным выпрямлением (не требуется диод Шоттки), с токовым управлением (current mode) и фиксированной частотой коммутации.

Особенности микросхем 5320ЕА02, 5320ЕВ02:

- диапазон напряжения питания от 2,7 до 6 В;

- выходной ток до 1,2 А;

- ограничение выходного тока в каждом такте;

- частота коммутации 1,2 МГц;

- снижение частоты коммутации при перегрузке;
- температурная защита;

- низкое напряжение считывания обратной связи 0,8 в;

- основной силовой ключ на р-канальном транзисторе 270 мОм;

- ключ синхронного выпрямителя на п-канальном транзисторе 280 мОм;

- диод Шоттки не требуется;

- вход (EN) для перевода микросхемы в режим с низким энергопотреблением.

Три последующие группы типономиналов серии 5320 расширяют очень популярное у разработчиков ВИП семейство импульсных стабилизаторов напряжения SIMPLE SWITCHER" от ф. National Semiconductors (сейчас - Texas Instruments) и их многочисленных клонов отечественными микросхемами.

Микросхемы типа 5320ЕA03, $5320 \mathrm{EB03} \mathrm{(см.} \mathrm{рис.} \mathrm{4)}$ и 5320ЕA04, 5320ЕВ04 (см. рис. 5) выполнены по биполярной технологии и представляют собой понижающие преобразователи напряжения SIMPLE SWITCHER с управлением по напряжению (voltage mode) и с фиксированной частотой коммутации.

Особенности микросхем 5320ЕА03, 5320ЕВ03, 5320ЕА04, 5320Ев04:

- диапазон напряжения питания от 6 до 40 B;

- выходной ток до 3 А;

- ограничение выходного тока в каждом такте;

- фиксированная частота коммутации 150 и 52 кГц;

- встроенная частотная компенсация стабилизатора;

- защита от перегрузки и короткого замыкания;

- температурная защита;

- вход (SD) для перевода микросхемы в режим с низким энергопотреблением.

\footnotetext{
SIMPLE SWITCHER - торговая марка Texas Instruments.
} 


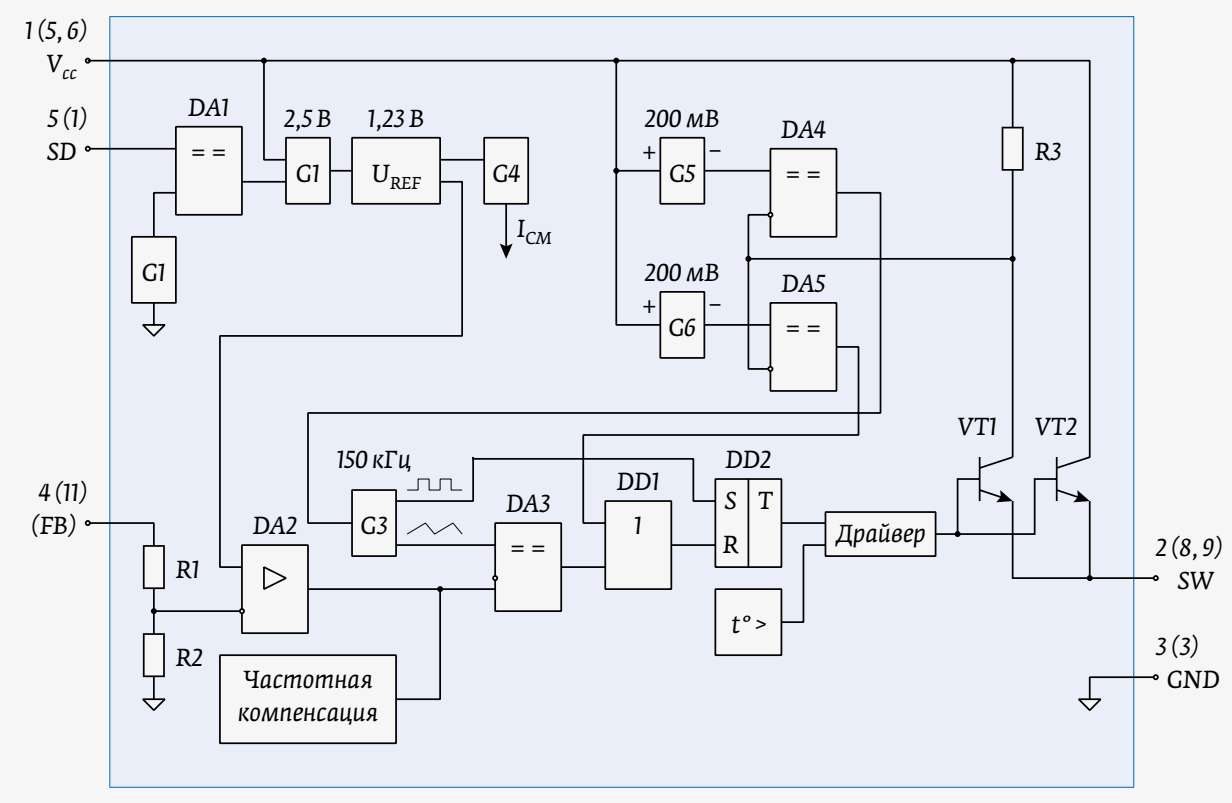

Рис. 4. Схема электрическая функциональная микросхем типа 5320ЕА03, 5320EB03

Между собой микросхемы типа 5320ЕA03, 5320ЕВ03 и микросхемы типа 5320ЕА04, 5320ЕВ04 различаются незначительно. У первых выше частота коммутации 150 кГц против 52 кГц у вторых, и двухуровневая логика отработки ограничения импульсного тока силового ключа.

Микросхемы типа 5320EA05, 5320EB05 (см. рис. 6) выполнены по БиКДМОП-технологии, которые также можно отнести к семейству SIMPLE SWITCHER, представляют собой понижающие преобразователи напряжения с управлением по напряжению (voltage mode) и с фиксированной частотой коммутации.

\section{Особенности микросхем 5320ЕА05, 5320ЕВ05:}

- диапазон напряжения питания от 8 до 27 В;

- выходной ток до 3 А;
- ограничение выходного тока в каждом такте;

- фиксированная частота коммутации 250 кГц;

- встроенная частотная компенсация стабилизатора;

- защита от перегрузки и короткого замыкания;

- температурная защита;

- вход (EN) для перевода микросхемы в режим с низким энергопотреблением.

Микросхема типа 5320ЕА06 (см. рис. 7) выполнена по биполярной технологии и представляет собой понижающий преобразователь напряжения с управлением по напряжению (voltage mode) и с фиксированной частотой коммутации. В отличие от SIMPLE SWITCHER, обладает расширенным функционалом, позволяющим ей более легко адаптироваться под не совсем стандартные применения.

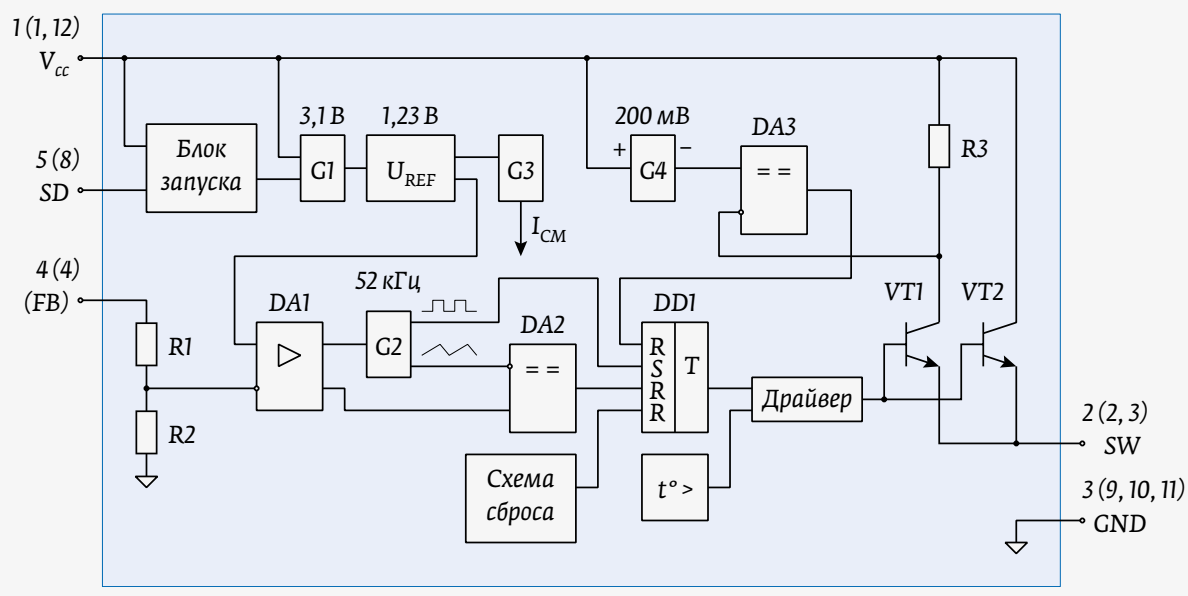

Рис. 5. Схема электрическая функциональная микросхем типа 5320EA04, 5320EB04 


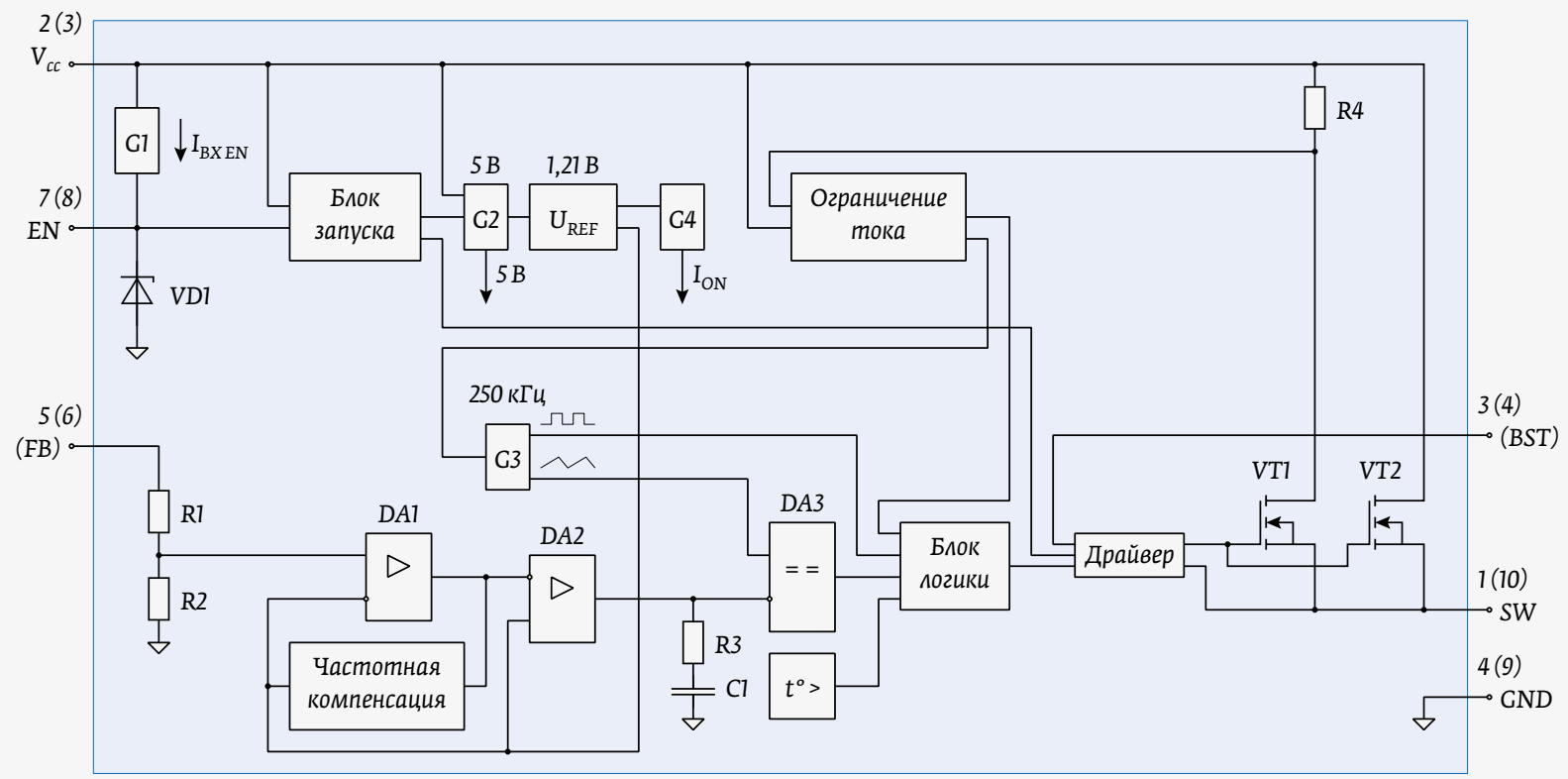

Рис. 6. Схема электрическая функциональная микросхем типа 5320ЕА05, 5320ЕВ05

\section{Особенности микросхем 5320ЕА06:}

- диапазон напряжения питания от 10 до 40 B;

- выходной ток до 2 А;

- ограничение выходного тока в каждом такте;

- фиксированная частота коммутации 100 кГц;

- сброс частоты коммутации при перегрузке;
- специальный драйвер силового ключа с форсирующей цепью;

- защита от перегрузки и короткого замыкания;

- программируемый уровень срабатывания ограничения тока;

- ассиметричный усилительсигнала рассогласования;

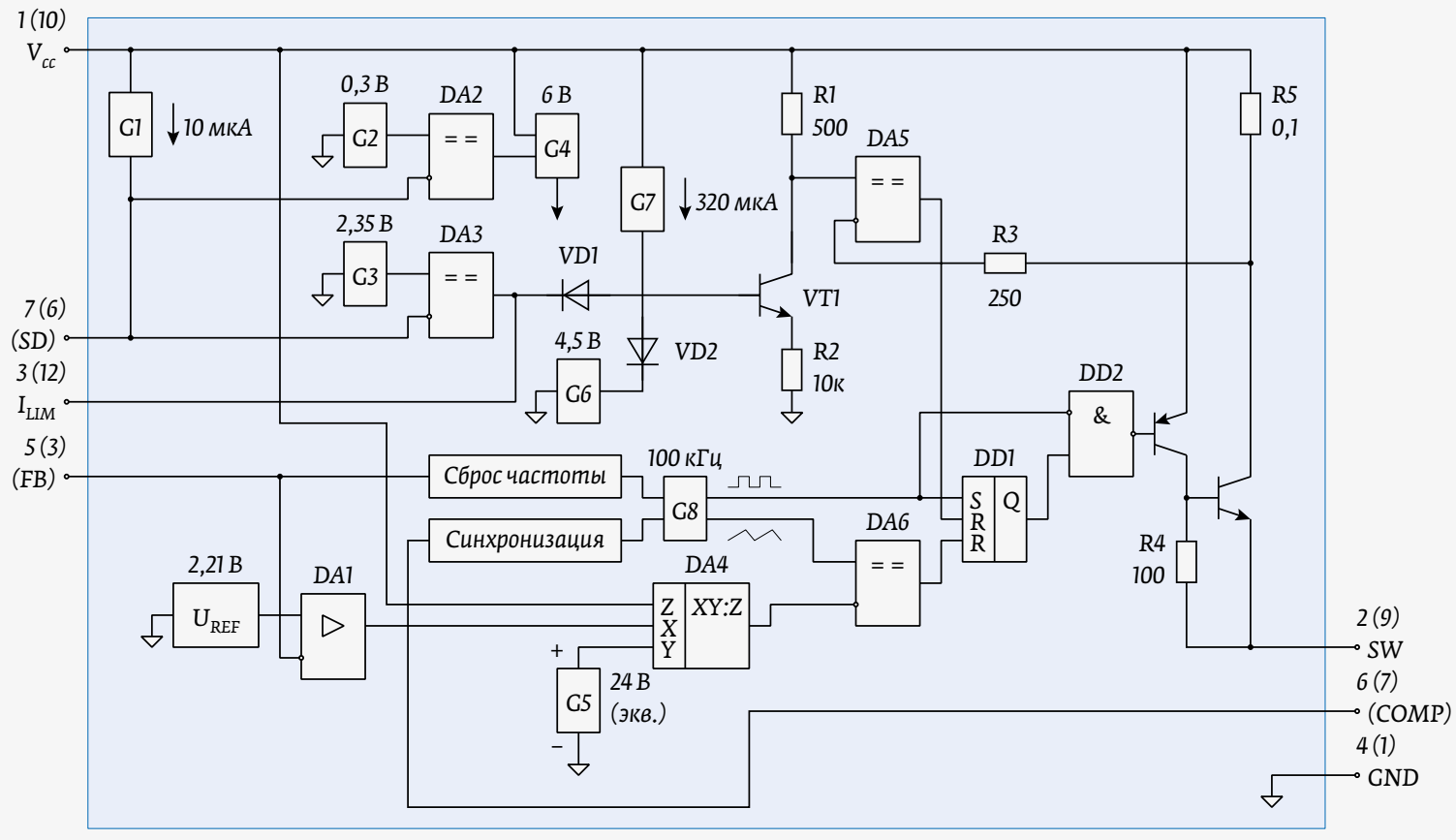

Рис. 7. Схема электрическая функциональная микросхем типа 5320ЕА06 
В соответствии с государственной программой Российской Федерации по импортозамещению предприятием AO «ГРУППА КРЕМНИЙ ЭЛ» разработана $и$ освоена серия импульсных стабилизаторов напряжения с встроенным силовым ключом для космической техники и общепромышленной аппаратуры. Изделия выпускаются в металлокерамических корпусах, в металлополимерных корпусах для поверхностного монтажа, а также в бескорпусном исполнении. Соответствуют по техническим характеристикам широко распространенным импортным аналогам.

\section{Импульсные стабилизаторы напряжения серии 5320}

понижающие и понижающе-повышающие. Регулируемые и фиксированные на ряд выходных напряжений, с встроенным силовым ключом, ограничением выходного тока в каждом такте, температурной защитой.
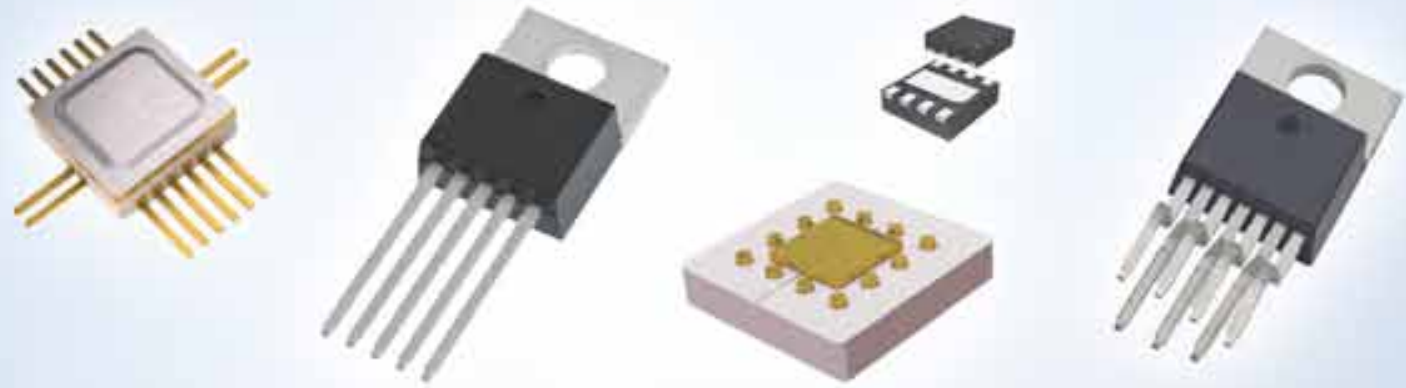

\begin{tabular}{|c|c|c|c|c|c|c|c|c|}
\hline \multirow[t]{2}{*}{$\begin{array}{c}\text { Tип } \\
\text { микросхемы }\end{array}$} & \multirow[t]{2}{*}{$\begin{array}{l}\text { Ряд выходных } \\
\text { напряжений }\end{array}$} & \multirow{2}{*}{\begin{tabular}{|c|} 
Bыходной \\
ток, \\
Ins, A \\
He бonee \\
\end{tabular}} & \multicolumn{2}{|c|}{$\begin{array}{c}\text { पастота } \\
\text { генерирования, } \\
\mathrm{f}_{\mathrm{r}, \mathrm{k} \text {, } \mathrm{s}}\end{array}$} & \multicolumn{2}{|c|}{$\begin{array}{l}\text { Напряжение питания, } \\
\qquad \mathrm{U}_{n}, \mathrm{~B} \\
\end{array}$} & \multirow{2}{*}{$\begin{array}{c}\text { Условное } \\
\text { обозначение } \\
\text { корпуса }\end{array}$} & \multirow[t]{2}{*}{$\begin{array}{c}\text { Ближсайтий } \\
\text { фүнкциональный } \\
\text { aналог }\end{array}$} \\
\hline & & & нe менеe & He 6onee & не менее & He 6 onee & & \\
\hline 5320EA01 & регулируемый & \multirow{2}{*}{1} & \multirow{2}{*}{170} & \multirow{2}{*}{240} & \multirow{2}{*}{ - } & \multirow{2}{*}{30} & $5225.10-1$ & \multirow{2}{*}{ ADP3050 } \\
\hline 5320EB01 & 2,$5 ; 3,5 ; 5$ & & & & & & $\mathrm{H} 04.16-2 \mathrm{~B}$ & \\
\hline 5320EA02 & регулируемый & \multirow{2}{*}{1,2} & \multirow{2}{*}{1000} & \multirow{2}{*}{1500} & \multirow{2}{*}{ - } & \multirow{2}{*}{6} & $5225.10-1$ & \multirow{2}{*}{ MP2012 } \\
\hline $5320 \mathrm{EBO} 2$ & 1,$5 ; 1,6 ; 1,8 ; 3,3$ & & & & & & $\mathrm{H} 04.16-2 \mathrm{~B}$ & \\
\hline 5320EA03 & регулируемый & \multirow{2}{*}{3} & \multirow{2}{*}{110} & \multirow{2}{*}{173} & \multirow{2}{*}{ - } & \multirow{2}{*}{40} & $1501.5 \cdot 7$ & \multirow{2}{*}{ LM2596 } \\
\hline $5320 E B 03$ & 3,$3 ; 5 ; 12$ & & & & & & MK KT-119-1 & \\
\hline 5320EA04 & регулируемый & \multirow{2}{*}{3} & \multirow{2}{*}{42} & \multirow{2}{*}{63} & \multirow{2}{*}{ - } & \multirow{2}{*}{40} & $1501.5 \cdot 7$ & \multirow{2}{*}{ LM2576 } \\
\hline 5320EBO4 & 3,$3 ; 5 ; 12 ; 15$ & & & & & & MK KT-119-1 & \\
\hline 5320EA05 & регулируемый & \multirow{2}{*}{3} & \multirow{2}{*}{225} & \multirow{2}{*}{280} & \multirow{2}{*}{8} & \multirow{2}{*}{24} & \multirow{3}{*}{$\begin{array}{c}1505.7-D \\
\text { MK KT-119-1 }\end{array}$} & $1 M 2676$ \\
\hline 5320EB05 & 3,$3 ; 5 ; 12$ & & & & & & & LIVIZO \\
\hline 5320EA06 & регулируемый & 2 & 85 & 125 & 10 & 40 & & LT1076 \\
\hline 5320EA07 & регулируемый & 1 & 450 & 550 & - & 40 & $\begin{array}{l}5225.10-1 \\
H 04.16-2 B\end{array}$ & LT1372 \\
\hline 5320EA08 & perулируемый & 5 & 85 & 115 & - & 40 & $\begin{array}{c}1501.5-7 \\
\text { MK KT-119-1 }\end{array}$ & LT1170 \\
\hline
\end{tabular}

Все микросхемы рассчитаны на диапазон рабочих температур от минус $60^{\circ} \mathrm{C} A 0+125^{\circ} \mathrm{C}$

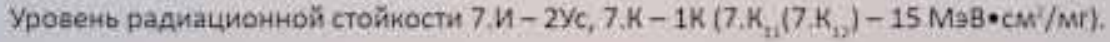


Таблица 1. Основные технические параметры импульсных понижающих стабилизаторов серии 5320

\begin{tabular}{|c|c|c|c|c|c|c|c|c|c|c|c|}
\hline \multirow{3}{*}{$\begin{array}{l}\text { Условное } \\
\text { обозначение } \\
\text { микросхемы }\end{array}$} & \multirow[t]{3}{*}{$\begin{array}{l}\text { Выходное } \\
\text { напряжение }\end{array}$} & \multicolumn{7}{|c|}{$\begin{array}{c}\text { Квалификационные параметры в нормальных климатических условиях } \\
\text { (буквенное обозначение, единица измерения) }\end{array}$} & \multirow{3}{*}{$\begin{array}{c}\text { Условное } \\
\text { обозначение } \\
\text { корпуса }\end{array}$} & \multirow[t]{3}{*}{$\begin{array}{l}\text { Обозначение } \\
\text { ТУ исполнения }\end{array}$} & \multirow{3}{*}{$\begin{array}{c}\text { Бли- } \\
\text { жайший } \\
\text { функцио- } \\
\text { нальный } \\
\text { аналог }\end{array}$} \\
\hline & & \multicolumn{2}{|c|}{$\begin{array}{l}\text { Напряжение } \\
\text { считывания } \\
\text { обратной } \\
\text { связи/ выходное } \\
\text { напряжение, } \\
U_{\text {счос }} / U_{\text {выхх }} \text { B }\end{array}$} & \multirow{2}{*}{$\begin{array}{c}\text { Выход- } \\
\text { ной } \\
\text { ток, } \\
\text { I вых, }_{1} \text { A } \\
\begin{array}{c}\text { не } \\
\text { более }\end{array}\end{array}$} & \multicolumn{2}{|c|}{$\begin{array}{c}\text { Частота } \\
\text { генерирования, } \\
f_{\Gamma,} \text { кГц }\end{array}$} & \multicolumn{2}{|c|}{$\begin{array}{c}\text { Напряжение } \\
\text { питания, } \\
\text { Un }_{n} \text { B }\end{array}$} & & & \\
\hline & & $\begin{array}{l}\text { не } \\
\text { менее }\end{array}$ & $\begin{array}{l}\text { не } \\
\text { более }\end{array}$ & & $\begin{array}{l}\text { не } \\
\text { менее }\end{array}$ & $\begin{array}{l}\text { не } \\
\text { более }\end{array}$ & $\begin{array}{l}\text { не } \\
\text { менее }\end{array}$ & $\begin{array}{l}\text { не } \\
\text { более }\end{array}$ & & & \\
\hline 1 & 2 & 3 & 4 & 5 & 6 & 7 & 8 & 9 & 10 & 11 & 12 \\
\hline 5320EA015 & Регулилируемое & 1,160 & 1,240 & 1,0 & 170 & 240 & - & 30 & $5225.10-1$ & AEHB.431420.457-01 TY & (ADP3050) \\
\hline 5320EA015A & & & & & & & & & $\mathrm{H} 04.16-2 \mathrm{~B}$ & & \\
\hline 5320EB01A5 & Фиксированное & 2,400 & 2,600 & & & & & & 5225.10-1 & & \\
\hline 5320ЕВ01Б5 & & 3,200 & 3,400 & & & & & & & & \\
\hline 5320EB01B5 & & 4,850 & 5,150 & & & & & & & & \\
\hline 5320ЕB01A5A & & 2,400 & 2,600 & & & & & & $\mathrm{H} 04.16-2 \mathrm{~B}$ & & \\
\hline 5320ЕВ01Б5A & & 3,200 & 3,400 & & & & & & & & \\
\hline $5320 \mathrm{~EB} 01 \mathrm{~B} 5 \mathrm{~A}$ & & 4,850 & 5,150 & & & & & & & & \\
\hline 5320EA025 & Регулилируемое & - & 0,800 & 1,2 & 1000 & 1500 & - & 6 & $5225.10-1$ & AEHB.431420.457-02 TУ & (MP2012) \\
\hline 5320EA025A & & & & & & & & & $\mathrm{H} 04.16-2 \mathrm{~B}$ & & \\
\hline 5320 EB02A5 & Фиксированное & 1,455 & 1,545 & & & & & & $5225.10-1$ & & \\
\hline 5320 EB02Б5 & & 1,550 & 1,650 & & & & & & & & \\
\hline 5320ЕВ02В5 & & 1,745 & 1,855 & & & & & & & & \\
\hline 5320 EВ02Г5 & & 3,200 & 3,400 & & & & & & & & \\
\hline $5320 \mathrm{~EB} 02 \mathrm{~A} 5 \mathrm{~A}$ & & 1,455 & 1,545 & & & & & & $\mathrm{H} 04.16-2 \mathrm{~B}$ & & \\
\hline 5320 ЕВ02Б5А & & 1,550 & 1,650 & & & & & & & & \\
\hline $5320 \mathrm{~EB} 02 \mathrm{~B} 5 \mathrm{~A}$ & & 1,745 & 1,855 & & & & & & & & \\
\hline 5320 ЕВ02Г5А & & 3,200 & 3,400 & & & & & & & & \\
\hline
\end{tabular}

- встроенный умножитель для организации прямой связи по входному напряжению;

- возможность внешней синхронизации;

- вход (SD) для перевода микросхемы в режим с низким энергопотреблением.

Микросхемы типа 5320ЕА07 (см. рис. 8) представляют собой интегральные высокочастотные импульсные регуляторы, предназначенные для применения в стабилизаторах напряжения с различными топологиями преобразования: повышающий, понижающий, обратноходовой, прямоходовой, инвертирующий, повышающе-понижающий
(SEPIC) и преобразователь Кука. Это наиболее функционально насыщенные микросхемы серии 5320. Микросхемы выполнены по биполярной технологии.

Особенности микросхем 5320ЕА07:

- диапазон напряжения питания от 2,7 до 40 B;

- выходной ток до 1 А;

- ограничение выходного тока в каждом такте;

- фиксированная частота коммутации 500 кГц;

- сброс частоты коммутации при перегрузке;

- специальный драйвер силового ключа со схемой ограничения насыщения; 
Таблица 1. Продолжение

\begin{tabular}{|c|c|c|c|c|c|c|c|c|c|c|c|}
\hline \multirow{3}{*}{$\begin{array}{l}\text { Условное } \\
\text { обозначение } \\
\text { микросхемы }\end{array}$} & \multirow[t]{3}{*}{$\begin{array}{l}\text { Выходное } \\
\text { напряжение }\end{array}$} & \multicolumn{7}{|c|}{$\begin{array}{c}\text { Квалификационные параметры в нормальных климатических условиях } \\
\text { (буквенное обозначение, единица измерения) }\end{array}$} & \multirow{3}{*}{$\begin{array}{c}\text { Условное } \\
\text { обозначение } \\
\text { корпуса }\end{array}$} & \multirow[t]{3}{*}{$\begin{array}{l}\text { Обозначение } \\
\text { ТУ исполнения }\end{array}$} & \multirow{3}{*}{$\begin{array}{c}\text { Бли- } \\
\text { жайший } \\
\text { функцио- } \\
\text { нальный } \\
\text { аналог }\end{array}$} \\
\hline & & \multicolumn{2}{|c|}{$\begin{array}{c}\text { Напряжение } \\
\text { считывания } \\
\text { обратной } \\
\text { связи / выходное } \\
\text { напряжение, } \\
U_{\text {счос }} / U_{\text {вых, }} \text { B }\end{array}$} & \multirow{2}{*}{$\begin{array}{c}\text { Выход- } \\
\text { ной } \\
\text { ток, } \\
\text { I вых, } A \\
\\
\text { не } \\
\text { более }\end{array}$} & \multicolumn{2}{|c|}{$\begin{array}{c}\text { Частота } \\
\text { генерирования, } \\
f_{\Gamma}, \text { кГц }\end{array}$} & \multicolumn{2}{|c|}{$\begin{array}{c}\text { Напряжение } \\
\text { питания, } \\
U_{\Pi}, B\end{array}$} & & & \\
\hline & & $\begin{array}{c}\text { не } \\
\text { менее }\end{array}$ & $\begin{array}{l}\text { не } \\
\text { более }\end{array}$ & & $\begin{array}{c}\text { не } \\
\text { менее }\end{array}$ & $\begin{array}{l}\text { не } \\
\text { более }\end{array}$ & $\begin{array}{c}\text { не } \\
\text { менее }\end{array}$ & $\begin{array}{c}\text { не } \\
\text { более }\end{array}$ & & & \\
\hline 1 & 2 & 3 & 4 & 5 & 6 & 7 & 8 & 9 & 10 & 11 & 12 \\
\hline 5320 EA031 & Регулилируемое & 1,200 & 1,350 & 3,0 & 110 & 173 & - & 40 & $1501.5-7$ & AEHB.431420.457-01 Ty & (LM2596) \\
\hline 5320 EA035 & & & & & & & & & MK KT-119-1 & & \\
\hline 5320EB03Al & Фиксированное & 1,710 & 1,890 & & & & & & $1501.5-7$ & & \\
\hline 5320EB03Б1 & & 2,380 & 2,625 & & & & & & & & \\
\hline 5320EB03B1 & & 3,135 & 3,465 & & & & & & & & \\
\hline 5320ЕВ03Г1 & & 4,800 & 5,250 & & & & & & & & \\
\hline 5320ЕВ03Д1 & & 11,400 & 12,600 & & & & & & & & \\
\hline 5320ЕВ03A5 & & 1,710 & 1,890 & & & & & & MK KT-119-1 & & \\
\hline 5320ЕВ03Б5 & & 2,380 & 2,625 & & & & & & & & \\
\hline 5320ЕВ03В5 & & 3,135 & 3,465 & & & & & & & & \\
\hline 5320ЕВ03Г5 & & 4,800 & 5,250 & & & & & & & & \\
\hline 5320ЕВ03Д5 & & 11,400 & 12,600 & & & & & & & & \\
\hline 5320 EA041 & Регулилируемое & 1,180 & 1,286 & 3,0 & 42 & 63 & - & 40 & $1501.5-7$ & AЕНB.431420.457-01 TУ & (LM2576) \\
\hline 5320EA045 & & & & & & & & & MK KT-119-1 & & \\
\hline 5320EB04Al & Фиксированное & 2,375 & 2,625 & & & & & & $1501.5-7$ & & \\
\hline 5320EB04Б1 & & 3,135 & 3,465 & & & & & & & & \\
\hline 5320EB04B1 & & 4,750 & 5,250 & & & & & & & & \\
\hline 5320ЕВ04Г1 & & 11,400 & 12,600 & & & & & & & & \\
\hline 5320ЕB04A5 & & 2,375 & 2,625 & & & & & & MK KT-119-1 & & \\
\hline 5320ЕВ04Б5 & & 3,135 & 3,465 & & & & & & & & \\
\hline 5320ЕВ04B5 & & 4,750 & 5,250 & & & & & & & & \\
\hline 5320ЕВ04Г5 & & 11,400 & 12,600 & & & & & & & & \\
\hline
\end{tabular}

- возможность внешней синхронизациичерез вход(S/S);

- вход (S/S) также используется для перевода микросхемы в режим с низким энергопотреблением;

- вход (NFB) дополнительного усилителя сигнала рассогласования для отрицательного выходного напряжения;
- вывод (СОМР) - выход основного усилителя сигнала рассогласования и вход ШИМ-компаратора;

- вывод (СОМР) также используется для частотной коррекции;

- температурная защита.

Микросхемы типа 5320ЕА08 (см. рис. 9) представляют собой функционально упрощенную версию микросхем типа 


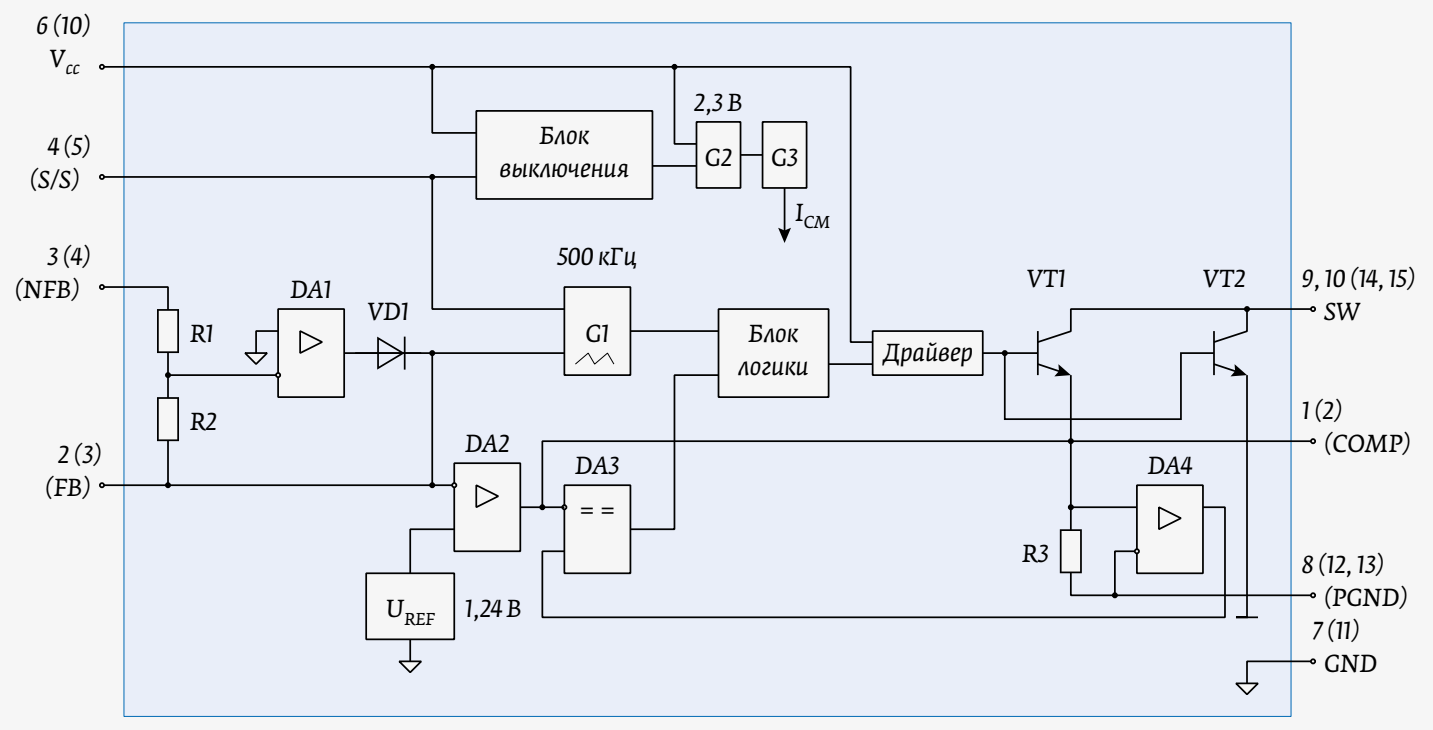

Рис. 8. Схема электрическая функциональная микросхем типа 5320ЕА07

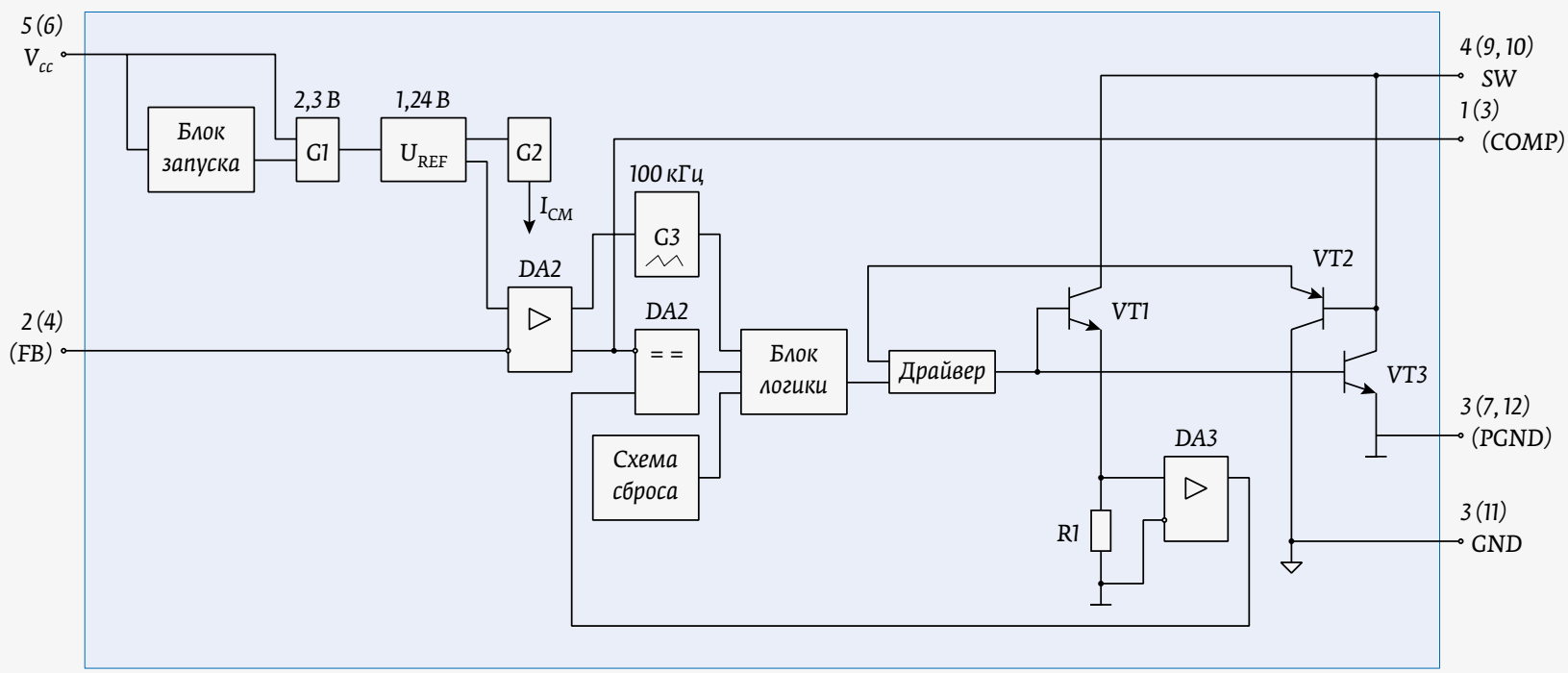

Рис. 9. Схема электрическая функциональная микросхем типа 5320ЕА08

5320ЕА07, но обладают силовым ключом на ток до 5 А. Микросхемы так же выполнены по биполярной технологии и предназначены для построения мощных, в первую очередь, повышающих преобразователей.

Новая серия микросхем 5320 импульсных стабилизаторов напряжения со встроенным силовым ключом серийно освоена в АО «Группа Кремний ЭЛ». Большое количество типов и типономиналов, входящих в серию, их функциональное разнообразие позволят потребителям микросхем разрабатывать новую аппаратуру значительно быстрее и качественнее, успешно решать задачи импортозамещения. Широкийдиапазон рабочихтемператур, высокий уровень стойкости к ВВФ и разнообразные варианты корпусов микросхем позволяют их применять в наземной и космической технике, авиации, надводной и подводной технике ВМФ, а также в общепромышленной аппаратуре. 


\section{АКЦИОНЕРНОЕ ОБЩЕСТВО «ЗАВОД ПОЛУПРОВОДНИКОВЫХ ПРИБОРОВ»}

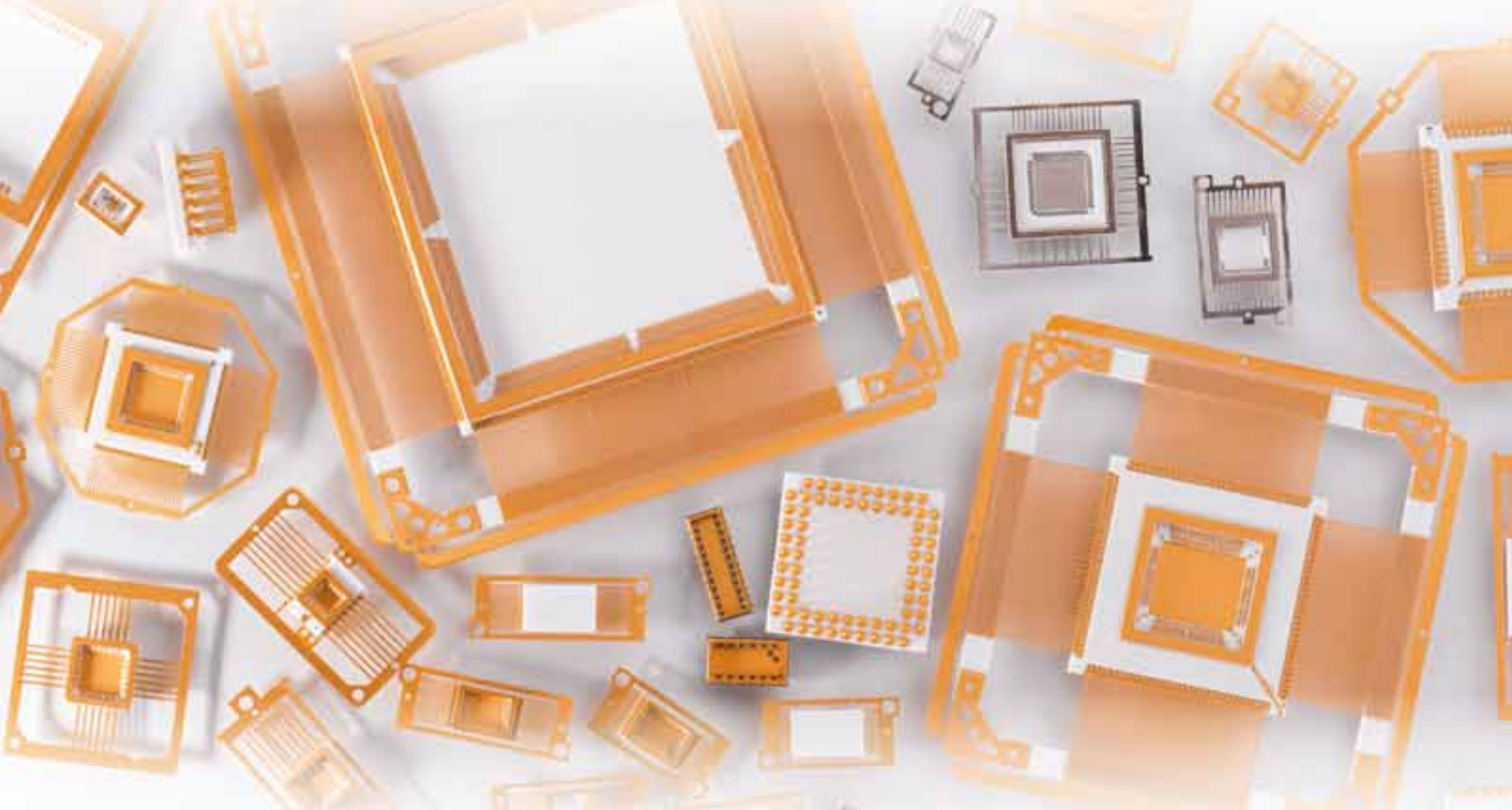

Предприятие располагает научно-технической и испытательной базой для проведения исследований, разработки и выпуска новой продукции

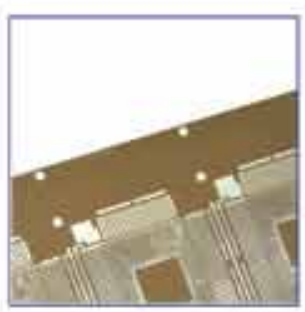

Выводные рамки

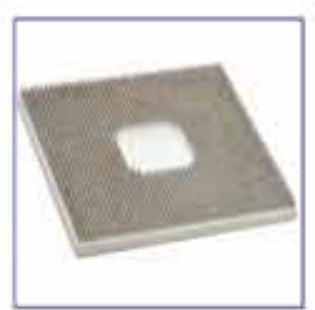

Mеталnокерамические корпуса

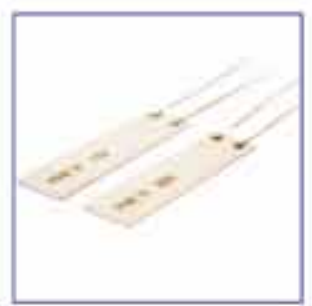

Нагревательные элементы

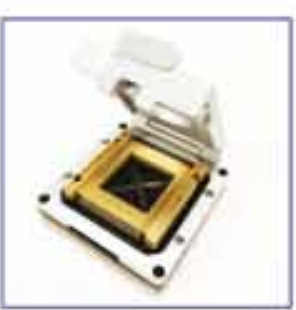

Контактные устройства

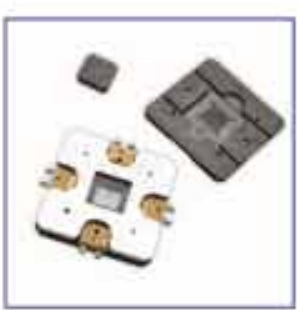

Графитовая оснастка

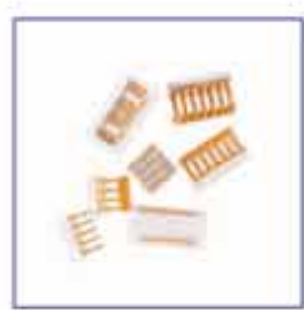

Оптозлектронные кopnyca

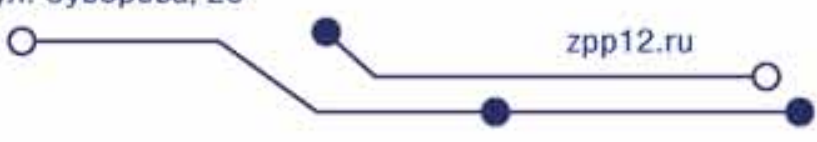

